\title{
The Need for a School-based Student Obesity Prevention Program: Perceptions of Rural Elementary Principals
}

\author{
Travis D. Armstrong \\ Wichita Falls Independent School District \\ Clementine Msengi \\ Sandra Harris \\ Lamar University
}

This phenomenological study investigated the perceptions of elementary principals regarding the need for a schoolbased student obesity prevention at eight, rural elementary schools in North Central Texas. Face to face interviews were the primary method of data collection from the eight participants. Findings indicated that school-based obesity prevention programs are needed to decrease the occurrence of student obesity, improve student diets and health related behaviors, educate families on obesity prevention measures, and improve the academic performance of students. The need to inform and include relevant stakeholders in the creation and implementation of school-based obesity prevention programs was identified as an essential component to the success of the program. The findings provide school leaders with components needed for an effective school-based obesity prevention program along with barriers for consideration.

Keywords: obesity prevention, rural school leaders, academic performance

Ogden, Carroll, Kit, and Flegal (2014) reported the percentage of children aged 6-11 years in the United States who were obese has increased from 7\% in 1980 to nearly $18 \%$ in 2012. During this same time period, adolescents aged 12-19 years old who were obese has increased from 5\% to nearly 21\%.

According to Rural Health Information Hub (2015), obesity rates in rural communities are higher than the nation as a whole. Several factors contributing to this include higher poverty rates, sedentary rural jobs and limited access to obesity prevention and treatment services. Other issues include lack of sufficient exercise facilities and infrastructure to encourage physical activity and limited access to healthy and affordable food. Nutritional practices such as frequent consumptions of high fat diets, less consumptions of fruits and vegetables also lead to higher rated of obesity in rural areas (Stratis Health, 2016).

In fact, in 2012 nearly one third of US children and adolescents were overweight (Centers for Disease Control and Prevention, 2015. There are long-term health effects related to obesity, such as greater risk for bone and joint problems, sleep apnea, social and psychological problems, and a greater likelihood to become an obese adult (Office of the Surgeon General, 2010). Thus the purpose of this study was to explore the need for the school to implement student obesity prevention programs as perceived by rural school principals. The research questions guiding this study were:

1. Why do school leaders perceive there is a need for school-based obesity prevention programs?

2. What are the aspects of a school based obesity prevention program that school leaders feel are essential to conducting a successful and effective program?

3. What barriers do school leaders encounter in conducting an obesity prevention program?

\section{Literature Review}

Childhood obesity carries over into the school setting, having a negative impact on students in a multitude of ways ( $\mathrm{Li}, 2012)$. Jansen et al. (2014) concluded that when students enter kindergarten, a high BMI was shown to be a risk factor for students to be victimized or bullied based on the physical appearance of being overweight. Campos, Sigulem, Moraes, Escrivao, and Fisberg (2006) conducted a study that found obese students performed significantly lower on IQ testing compared to students in the normal weight range. Tobin (2013) found that even when controlling for socioeconomic status, teacher experience, and school urbanicity, obese students acquired significantly lower test 
scores in reading (-11.15 points) and math (-11.13) compared to healthy weight peers. Prior studies also indicated that obese students were at higher risk of being retained (Falkner et al., 2011), obtaining a lower grade point average (Mosuwan, Lebel, Puetpaiboon, \& Junjana, 2009), missing more days of school compared to normal weight peers (Schwimmer, Burwinkle, \& Varni, 2003), and having low self-esteem (Florin, Shults, \& Stettler, 2011).

Walker (2011) emphasized that schools are an essential venue for primary prevention of children becoming overweight or obese due to the amount of hours per day students spend in school, the fact that one to two meals are consumed there, and resources including school nurses and physical education programs are already in place. Thus, obesity prevention programs in schools are needed to teach behavior modification and incorporate instructional programming to promote the practice of healthy eating and an active lifestyle. School officials and relevant personnel need to assess the needs of their school and determine an appropriate intervention program for obesity prevention (Power, Bindler, Goetz, \& Daratha, 2010).

Muriello et al. (2006) noted that overweight children and adolescents are at risk for numerous health related problems, including Type 2 diabetes, asthma, hypertension, high blood lipids, along with psychological vulnerabilities ranging from low selfesteem to depression. Muriello et al. argued that strong evidence exists that tracks obesity from childhood to adulthood. In fact, being overweight during adolescence is the single best predictor of adult obesity. Thus, as students are going through childhood and adolescence, it is an essential time to intervene as weight and health related issues arise. In the public school system, educators are charged and made responsible for the academic achievement of students as well as helping to build student's moral character and teaching them about good citizenship. However, educators should re-evaluate what they are doing to ensure that students maintain good physical, mental, and emotional health (Torre, Akre, \& Suris, 2010).

Utter et al. (2011) argued that school based trials for the prevention of obesity are an extension of many decades of prevention research targeting health-compromising behaviors in young people. The school setting is a logical place for obesity prevention, as it possesses a unique influence on child and adolescent nutrition. Utter et al. noted that school-based interventions allow for both interventions targeting individual behaviors and those collectively influencing the wider school and social environment need to be created and implemented in the best interest of our student's health and wellbeing.

According to the United States Department of Health and Human Services (USDHHS) (2014) there are several school-based obesity prevention programs in place. These include programs utilizing: nutrition education, physical education, parental involvement, and policy changes associated with obesity prevention, such as Healthy Hunger Free Kids Act, Chefs Move to Schools, Let's Move Salad Bars 2 Schools, and Let's Move! Child Care.

The USDHHS (2014) reported The Healthy Hunger Free Kids Act (HHFKA) was created in 2010 but not implemented in schools until 2014. Since 32 million students participate in the National School Lunch Program and 13 million students participate in the School Breakfast Program, it is important to assess school meal standards on a regular basis. The HHFKA requires school cafeterias to implement healthier, more nutritious school meal standards. New meal standards require cafeterias to: offer students both fruit and vegetables every day, increase whole grain rich foods, offer low fat or fat free milk, ensure proper portion sizes are distributed, and reduce saturated fat, trans fat, and sodium.

According to the USDHHS (2014), Chefs Move to Schools pairs chefs with schools to help improve students' health and nutrition. Chefs volunteer in the school and then partner with teachers, parents, nutritionists, food service directors, and campus administrators toward building a healthy school environment. Starting a school garden is one task where chefs can assist. The goal of starting the garden is to provide a hands-on learning environment where students can plant, care for, and watch vegetables grow.

The USDHS (2014) described another program, Let's Move Salad Bars 2 Schools, which is an initiative to include salad bars in school cafeterias. Inclusion of salad bars in the school would meet one of the requirements of the HHFKA. The initiative was developed by the Food Family Farming Foundation, the National Fruit and Vegetable Alliance, the United Fresh Produce Association Foundation, Whole Foods Market, and the former First Lady Michelle Obama. Mrs. Obama has 
challenged America to include salad bars in 6,000 schools.

The USDHHS (2014) noted that Let's Move! Child Care is a voluntary initiative to empower and offer support to childcare and early childhood education facilities. Providing children with a healthy start in childcare and early education programs is crucial to solving the childhood obesity problem. One out of every five children are overweight or obese by age six. This initiative provides child care providers with the opportunity to instill healthy choices in chilren that can assist in the prevention of childhood obesity at a later age. The program provides specific goals and objectives for providers to complete.

Cooper Institute (2014) reported that in Texas public schools, many students participate in the Fitnessgram. The Fitnessgram consists of healthrelated physical fitness tests that determine and assess aerobic capacity, endurance, flexibility, muscle strength, and body composition. BMI is also measured to provide schools with data on how many students are in a healthy weight range compared to those who are overweight or obese. This test does not focus on athletic performance. Fitnessgram focuses on criterion-referenced standards relevant to health related fitness based on levels of fitness required for good health. Every student's score is compared to the Healthy Fitness Zone (HFZ) standards developed by Fitnessgram's Scientific Advisory Board. This board is composed of physical activity and fitness scientists and practitioners. The HFZ standards are age and gender specific and allow for changes in maturation and growth.

Despite existing literature that describes the documented successes and failures of school-based obesity intervention programs, there are still too few schools implementing such programs (Power, Bindler, Goetz, \& Daratha, 2010). Torre, Akre, and Suris (2010) emphasized that their findings on successful school-based obesity intervention programs suggested that the program implemented must be tailored specifically for the campus and relevant to the campus' student population. However, little research exists that uncovers the beliefs and perceptions of school professionals on what the school's specific role should be in the prevention of obesity. Having the buy-in of school professionals, especially those in positions of leadership, in the creation and maintenance of school based obesity prevention programs is crucial. Therefore, their input needs to be solicited and used as an important piece in the creation of successful programs (Miller et al., 2012).

\section{Methodology}

The research design for this study was a phenomenological narrative inquiry approach since the researcher intended to understand the common meaning of the lived experiences of several individuals relating to a specific concept (Creswell, 2013). A purposeful sampling identified eight rural principals for interviews who met the following criteria: (a) the school had more than $55 \%$ of students identified as low socioeconomic status as determined by the Texas Education Agency, (b) the school was considered rural with no more than 550 students enrolled, (c) the school housed Pre-Kindergarten through Fourth Grade students or higher, (d) principals self-identified as having an in-depth knowledge of all curricular and extracurricular programs on their campus, and (e) principals believed that childhood obesity was a current issue among their student population. The rural elementary schools were located in North Central Texas and ranged in size from a population of 194 to 503 students. The percent of low socio-economic students ranged from $55.7 \%$ to $95.6 \%$. Four principals were male and four were female. The principals had served on the campus from two to nine years.

Approval was granted from the Lamar University Institutional Review Board (IRB). Access to the campus sites was granted by the superintendent of the respective school district. Prior to contacting the superintendents, each principal was contacted in order to determine their interest in participating in the study. To assure clarity of responses, participants were provided the following definition of a school based obesity prevention program prior to the interview: "programs designed to educate students on healthy food and beverage selection, physical education, and behavioral changes needed to prevent or decrease overweight and obesity in children" (Utter et al., 2011, p. 51).

In-depth, face to face interviews were scheduled and conducted. A guided protocol based on the research questions and the literature was created to provide an interview framework, Interviews were digitally recorded and later transcribed and each lasted approximately one hour. The researcher used the phenomenological analysis and representation approach detailed in Creswell (2013) by developing a list of significant statements from the text of 
interviewee's responses, grouping these statements into themes, creating a textural description, creating a structural description, and finally creating a composite description. An alias name was used for each participant and the school.

\section{Findings}

The purpose of this phenomenological narrative study was to explore the need for the school to implement student obesity prevention programs as perceived by rural school principals. Findings are presented based on research questions for the study

\section{Research Question One}

Research question one investigated why school leaders perceived the need for a school-based obesity prevention program on their campus. The themes that emerged included: parents not educating for healthy living, students maintaining unhealthy diet, and need for empowering students.

Parents not educating for healthy living. Six of the eight principals voiced the concern that parents were not educating children on proper exercise and diet habits. For example, one principal believed that students were becoming unhealthy due to a "lack of an appropriate amount of attention given to the child's health at home from [the] family." He felt these issues at home were "bleeding over" into the school setting and thus educators needed to address them.

Another principal responded in a similar manner when he commented:

I don't believe that parents are doing a good enough job educating their children about what healthy living is all about when it comes to exercise, and more importantly, when it comes to diet. This is where, you know, if the parents don't address what we feel like they should address at home, we feel a responsibility to address it at school.

Students maintaining unhealthy diet. All of the principals observed that students are maintaining an unhealthy diet. While some expressed concern that cafeteria food on their campus was lacking in nutritional value, other principals believed that cafeteria food had improved but noticed that students still would not eat the cafeteria food and would purchase snack foods instead. For example, one principal noted:
Right now, it's the lack of students selecting healthy food choices. You know, kids being on the free or reduced priced cafeteria meals. They do receive the appropriate choices but somehow or another, they always come up with lots of extra money that they can use to buy the chips and cookies.

We have more students here that are obese. I see too when you're talking about physical activity, we have some kids that will come in with a bag, we have a bakery up the street, that has donut holes because they're running late. The parents will comment, "Don't eat so much sugar today” as they send the child off with a bag of donuts. But then I also see some of the students, the girls especially, that don't want to participate in PE. They say, "I don't like that activity or I don't want to run, etc." So there's not that push [motivation] for the physical activity part of it either. At least there's no push from the student, which often means no push from the parent.

Another principal commented that students "will eat an ice cream cone and two bags of chips [without touching] what's on their tray." She suggested that while they know they are making a poor choice, they don't "know what impact that's going to have down the road."

Need for empowering students. All the principals emphasized the importance of empowering students to make healthy food choices. In addition to participants' concerns relating to students maintaining unhealthy food choices, a theme emerged that students must be empowered with the knowledge to make healthy food choices independently. One principal stated, "I think that kids need to understand that there are other food choices out there that they could be making." Another commented:

The kids don't have a knowledge of what's good for them anymore. They just have a negative perception of vegetables, or no perception at all... Just some teaching them why to eat healthy foods and why that's important is needed. They need information that can help them down the road.

Another principal focused on the need to empower students to make healthy food choices especially among the low socioeconomic students on his campus. He shared: 
I think, it's more about, again going back to the whole child, letting the child know that they don't have to be a product of their circumstances. They are truly a product of the choices they make... So, we need to educate students, to empower them, let them know they are leaders, and let them know they can do whatever they set their mind to and whatever they are good at which includes being healthy.

\section{Research Question Two}

Research question two asked participants about aspects of a school-based obesity prevention program that they considered essential to conducting a successful and effective program. The themes that emerged were: communicate to inform and involve stakeholders, demonstrate potential for improving eating habits, demonstrate potential to improve academics, and provide training.

\section{Communicate to inform and involve}

stakeholders. All principals indicated the importance of communicating to inform and include stakeholders in the program development and implementation. They emphasized the need and importance of including parents and relevant stakeholders in the program. Responses varied from simply informing parents and stakeholders of how the program would be conducted to welcoming their input in the development of a program. One principal discussed the need to obtain program buy-in by communicating the program to others. He stated, "The program needs to be well communicated to the community. They need to know what you're doing in order to buy into it."

Another principal emphasized the need for school administration to work collaboratively in the establishment of a program. This principal said, "In a district like this, it would need the food service director, the director of physical education and all administration involved. It would take everybody working together to promote it...” Another principal commented:

Well, I think that, for sure, you would need different avenues of communicating the program to others whether it's face to face, or phone calls ... or a school messenger system or emails. The program needs to be well communicated to the community. They need to know what you're doing in order to buy in to it. You still have to provide that face to face communication, because with low socioeconomic, a lot of people don't have internet access at home. Some people may not have cell phones. I just think you have to have a lot of ways to communicate the program.

Demonstrate potential for improving eating habits. All principals consistently emphasized their belief that a successfully executed school-based prevention program could enact positive changes to students' eating habits and decrease obesity. One principal noted, "I think you'd be able to see the fruits of your labor and see the benefits when you can see the kids and their families actually doing what you've taught them about good health." Another commented, "I would hope, after implementing this program ... they [students] would pick the healthier choice of drink, of for that matter, the healthier choice of food ... that would be a positive outcome.”

Another principal reiterated the notion of being able to observe students at his school making healthy food choices:

If this program worked, I would see kids, when they bring their lunch, making healthy lunch choices. You know talking about it [healthy food choices] with other kids and spreading the word, the knowledge. In classroom discussions with them, we would see what they are learning from it. You know, evaluating, are they really listening? Are they understanding that eating a bag of chips at night is not really healthy? It tastes good, but do they understand that it is not healthy? And then ultimately, obviously, seeing kids not be obese. That's the ultimate goal of it, educating them about that, so I would want to see them truly live that. I think that would definitely show its effectiveness.

\section{Demonstrate potential for improving} academics. All the principals believed that a program designed to prevent student obesity would demonstrate an important by-product - that of improving academic performance. As one principal said, "When I eat healthy and I exercise, I'm better at my job. So, I know if the kids are making better food choices, it will impact their academics!” Another referenced how the program could impact the overall well-being of students which, in turn, would increase productivity. She noted, "So, your well-being, which could be nutritional, physical, emotional, if that's better, you are going to see an increase in productivity in the classroom." 
One principal made the following comment regarding how healthy eating choices could result in improved behavior, academics and even emotions:

Again, going back to the whole child. If kids are making healthy choices, you know more or less, they are going to be more alert in class, they are going to make better choices behaviorally, academically, and emotionally. They're going to be more successful in life and obviously healthier. Their $21^{\text {st }}$ century skills, them working well together. Like I say, because they're going to feel better, I mean, you know how it is, when you eat healthy, you feel better and your mind's clearer. Why wouldn't this be true for these kids?

Provide training. The principals also emphasized the need for the program to provide training and education for all stakeholders. One principle noted the need for training for faculty and staff:

I think just for all of our staff members to become aware of what our actual numbers are with obesity and even for us. I think sometimes we as adults need to look at that and also just become more educated about what our students' lives are like. Whether it is the survey results to show them what kinds of foods are available to them in the home or related information, I think training, again, for adults here on campus to really define what healthy eating means. I think we need to go through the same type of educational program that the kids are going through so that we are all speaking the same language. We need to be reminding parents of these types of things in our conferences that school's not just focused on academics but also on the social and physical needs of the kids. Participants also emphasized the need to provide training to students and their families. This principal reflected, "Well, definitely an approach to getting the message out to families [is needed]. It would be for kids and it would have to be for the parents also. So, we would need a parent component, but it would need to be a school-wide thing."

Several participants also mentioned that logistics were important when considering training needs. For example, they discussed the need for time, money, personnel, and logistics as components of the training need. One principal described logistical procedures while providing insight into what he believed would be an effective strategy. He stated: You would need to have the personnel. You would have to have time over the summer or at least during your in-service, before we actually went back to school for the beginning of the year to get everybody on the same page. Training needs to be done prior to this time. That might be training from the service center, which in a district our size we lean on them a lot. You could have an expert maybe come out from the county, the hospital district, or something like that. I think that would be a great resource... I would imagine that most of the information, the material, the topic that you need to grasp, wouldn't cost you anything to do because you have people out there that would love to come and tell you about this. I just know that there are. It's a matter of contacting them to see if they are willing.

\section{Research Question Three}

Research question three asked participants to identify potential barriers they could encounter when implementing a school-based obesity prevention program. Three major themes emerged from this research question: lack of support, poor program implementation, and need for time and financial support.

Lack of support. All participants expressed concern over acquiring the support and buy-in of stakeholders for a school-based obesity prevention program. Some participants addressed concerns that they would have difficulty receiving the support of teachers for this program. Others stated that the main concern would be receiving support and participation from students and families. For example, one principal stated:

Buy-in would be needed from teachers, parents, and the community, and it's not something that would be taken care of overnight. It would take some time to implement this correctly, and you'd have to be willing to put the time in. And consistency is important. You know, another barrier I see is if a new principal comes in and doesn't see the value of the program, what happens then?

Another principal pointed out concerns that buy-in would be difficult to obtain from teachers due to their main obligation being the need to improve 
students' academic performance. He expressed that teachers felt the same pressures that administrators felt and that it would be a challenge to get teachers "on board" with the program.

Lifestyle issues were also addressed. For example, one principal voiced her concern that an obesity prevention program might contradict with lifestyles of those involved. She stated:

We do have some obese teachers ... and then asking them [the community] to change their lifestyle is something they could see as you stepping outside of the zone of things they think you should be concerned about. I mean, I could just see some parents asking, "Why don't you worry more about what you're teaching in that school for academics before you worry about what we're eating at home.”

Poor program implementation. Six participants discussed concerns that if the program was poorly implemented, it could lose its effectiveness in the prevention of obesity. They identified the need to make the program a high priority for the campus and implement it fully in order for it to be effective. For example, one principal said:

How many times have we tried things in education, where we have come along and then we try it and then we never talk about it again? Could this succumb to that? Why, of course. Anything could. If you value something, if you feel that it's a priority, if you really want to try to impact your students' and their parent's lives, you've got to stick with it. You've got to keep it out there in the forefront as one of the components of why we come to school. Just like reading or math or character education or whatever the case may be. It's just one of those things that if you want it to work, you've got to nurture it, grow it, make it part of your culture. To answer your question, if you don't, then it will be ineffective.

Another principal reiterated these concerns if the program was not implemented correctly or only done "halfway." A poorly implemented program, in her opinion, would confuse students, send mixed messages, and risk the loss of student buyin. However, she concluded, “And the thing is, it's not gonna work for every kid but it might hit a few. [pause] And then you hit a few more. Soon, you've got a group of healthy kids.”
Need for time and financial support. A common concern for all participants was the amount of time and money needed to correctly implement an obesity prevention program on campus. One principal noted, "It would take some time to implement this correctly, and you'd have to be willing to put the time in." Another commented, "I think time would certainly be an issue. Time is hard to find." There was also the concern that time devoted to this program could take away from instruction. This was a common response from participants. As one principal said:

You know, with the pressures of standardized testing that schools face on a yearly basis and the pressures that come from that and the consequences that come from performing poorly on that, it's tough for school systems to make sure that there is adequate time in the day for that [academics] and so time would be your biggest obstacle to overcome, finding that time to allow for this type of education.

Although participants were unsure of the financial cost of the program, several participants listed it as a variable to be considered. Several items were listed that cost money such as additional personnel, curriculum and instructional materials, and physical education equipment. After all, as one principal indicated, "Well, I think in general, most programs that we implement in education we run into financial snags. So that would be a concern adequate financial assistance.”

\section{Conclusions and Implications}

Based on the findings from this study, rural principals understand that there is a present need for childhood obesity prevention measures in rural elementary school settings. Evidence for this need is consistent with the findings of Ogden, Carroll, Kit, and Flegal (2014) that the school is an ideal setting to incorporate childhood obesity prevention measures. Despite the importance of obesity prevention, principals also noted the challenges inherent in establishing these programs.

Principals in this study expressed concern that obese students often come from homes where they perceive parents are failing to educate them on proper exercise and diet habits. Consequently, they acknowledged the importance of including and involving parents and families in any school-obesity prevention measures that the school may adopt. Safron, Cislak, and Gaspar (2011) analyzed the 
effectiveness of school-based obesity interventions and determined that interventions that involve parents were more effective in the reduction of overweight and obesity among school aged children. Additionally, Torre, Akre, and Suris (2010) indicated the need for government support and coordination of interventions balanced with providing schools with the freedom to adapt programs relevant to their specific student population. Integrating all school stakeholders in the prevention of obesity was also emphasized.

Principals suggested that student diets have changed, resulting in school principals' increased awareness of overweight and obese students. Students are selecting unhealthy beverages and food choices more often. This was attributed to the lack of education on proper nutrition at home and issues with the availability and access of healthy food and beverages. Thus, students at these eight rural schools were maintaining unhealthy behaviors leading to poor diets. This related to the expressed need to empower students with the education and knowledge needed to make healthy food and beverage choices. Obesity prevention programs are needed in schools to teach behavior modification and incorporate instructional programming to promote the practice of healthy eating and an active lifestyle.

These principals suggested that food and beverages served to students in the school cafeteria were potential contributing factors to the problem of childhood obesity. Some of this is tied to student behavior with food selection. For example, participants reported that students are often served a balanced meal but will discard the food served to them only to return and purchase snack items to be consumed. While opinions of cafeteria food varied by participant, all the principals suggested there is room for improvement. According to the US Department of Health and Human Services (2014), at the federal level, food served in the cafeteria is undergoing revision. The Healthy Hunger Free Kids Act initiated by the former First Lady, Michelle Obama, requires school cafeterias to implement healthier, more nutritious school meal standards. New meal standards require cafeterias to do the following: offer students both fruit and vegetables every day, increase whole grain rich foods, offer low fat or fat free milk, ensure proper portion sizes are distributed, and reduce saturated fat, trans fat, and sodium.

Findings in this study suggest the conclusion that rural principals believe that school-based childhood obesity programs have the potential to decrease the prevalence of obesity among children and contribute to improving students' academic performance. Participants discussed the "domino effect" of eating healthy, asserting that eating a healthy diet would allow a student to have more mental clarity, improved attention and focus in school, and have a positive impact on how they physically feel. Principals in this study believed that as result of these effects, academic performance would improve. Hollar (2010) found that schoolbased interventions are able to improve academic performance and physical health of low-income elementary students.

Several implications are made for educators to consider. Educators should employ the use of their School Health Advisory Council (SHAC), or other methods, to communicate the problem of childhood obesity to their school's community and explore methods of prevention. By representing a variety of stakeholders within the school community and outside the school community, SHAC's could effectively develop solutions for childhood obesity. The Texas Department of State Health Services (2012) suggested that the council's duties include recommending the appropriate curriculum for specific grade levels designed to prevent childhood obesity, Type 2 diabetes, and cardiovascular disease through the effective coordination of: nutrition services, health education, physical education and activity, parental involvement, and preventing the use of tobacco.

Today's educators, despite their many responsibilities, should explore ways to increase efforts in educating students on healthy food and beverage selection. This type of education can be covered in the students' health courses or as appropriate in classrooms or other venues. Whether the school creates or adopts a childhood obesity prevention program or not, data from this study indicate a need for changes in student diet. Again, how this is addressed in each school could be a collaborative decision made by the local SHAC.

We recommend that food service directors and related personnel evaluate food and beverages served in their school's cafeteria. According to the US Department of Health and Human Services (2014), although cafeteria workers must comply with a long list of federal regulations, several new options are available to schools as a result of the Healthy Hunger Free Kids Act (HHFKA) of 2010. These include 
Chefs Move to Schools and Let's Move Salad Bars 2 School. Once implemented, these programs should be studied over a period of time to determine their influence on students and their families.

We recommend that school leaders implement obesity prevention programs tailored to the needs of students on their campus. Consequently, school officials and relevant personnel need to assess the needs of their student population to determine an appropriate intervention program for obesity prevention (Power, Bindler, Goetz, \& Daratha, 2010).
Thus, a needs assessment is a valuable first step in the process of identifying specific prevention programs for each campus. Whether school leaders implement an existing program or create their own, a strong possibility exists that childhood obesity will continue to increase if educators do not intervene. Another consideration is that since obesity is a sensitive topic (STOP Obesity Alliance, 2014), we suggest that conversations related to weight issues or obesity prevention programs be designed to be empowering and nonjudgmental.

\section{References}

Campos, A., Sigulem, D., Moraes, D., Escrivão, A., \& Fisberg, M. (2006). Intelligent quotient of obese children and adolescents by the Weschler scale. Revista De Saúde Pública, 30(1), 85-90.

Centers for Disease Control and Prevention. (2015). Childhood obesity facts. Retrieved from http://www.cdc.gov/healthyschools/obesity/fact s.htm

Cooper Institute. (2014). Fitnessgram data results overview. Retrieved from http://www.cooperinstitute.org/vault/2440/web/ files/647.pdf

Creswell, J. W. (2013). Qualitative inquiry \& research design: Choosing among five approaches ( $3^{\text {rd }}$ ed.). Thousand Oaks, CA: SAGE Publications, Inc.

Falkner, N., Neumark-Sztainer, D., Story, M., Jeffery, R., Beuhring, T., \& Resnick, M. (2011). Social, educational, and psychological correlates of weight status in adolescents. Obesity Research, 9(1), 32-42.

Florin, T. A., Shults, J., \& Stettler, N. (2011). Perception of Overweight Is Associated With Poor Academic Performance in US Adolescents. Journal of School Health, 81(11), 663-670. doi:10.1111/j.1746-

1561.2011.00642.x

Hollar, D., Messiah, S. E., Lopez-Mitnik, G., Hollar, T., Almon, M., \& Agatston, A. S. (2010). Effect of a Two-Year Obesity Prevention Intervention on Percentile Changes in Body Mass Index and Academic Performance in Low-Income Elementary School Children. American Journal of Public Health, 100(4), 646-653.

Jansen, P. W., Verlinden, M., Dommisse-van Berkel, A., Mieloo, C. L., Raat, H., Hofman, A., \&
Tiemeier, H. (2014). Teacher and Peer Reports of Overweight and Bullying Among Young Primary School Children. Pediatrics, 134(3), 473-480. doi:10.1542/peds.2013-3274

Miller, A. L., Horodynski, M. A., Brophy Herb, H. E., Peterson, K. E., Contreras, D., Kaciroti, N., \& Lumeng, J. C. (2012). Enhancing selfregulation as a strategy for obesity prevention in Head Start preschoolers: the growing healthy study. BMC Public Health, 12(1), 1040-1048. doi:10.1186/1471-2458-12-1040

Mosuwan, L., Lebel, L., Puetpaiboon, A., \& Junjana, C. (2009). School performance and weight status of children and young adolescents in a transitional society in Thailand. International Journal of Obesity \& Related Metabolic Disorders, 23(3), 272.

Muriello, L., Driskell, M., Sherman, K., Johnson, S., Prochaska, J., \& Prochaska, J. (2006).

Acceptability of a school-based intervention for prevention of adolescent obesity. Journal of School Nursing (Allen Press Publishing Services Inc.), 22(5), 269-277. doi:10.1177/10598405060220050501

Office of the Surgeon General. (2010). The Surgeon's General's Vision for a Healthy and Fit Nation. Rockville, MD., US Department of Health and Human Services.

Ogden, C.L., Carroll, M.D., Kit, B.K., \& Flegal, K.M. (2014). Prevalence of childhood and adult obesity in the United States, 2011-2012. Journal of the American Medical Association, 311(8), 806-814.

Power, T. G., Bindler, R. C., Goetz, S., \& Daratha, K. B. (2010). Obesity Prevention in Early Adolescence: Student, Parent, and Teacher 
Views. Journal of School Health, 80(1), 13-19. doi:10.1111/j.1746-1561.2009.00461.x

Rural Health Information Hub. (2015). Rural obesity and weight control. Retrieved from https://www.ruralhealthinfo.org/

Safron, M., Cislak, A., Gaspar, T., \& Luszczynska, A. (2011). Effects of School-based Interventions Targeting Obesity-Related Behaviors and Body Weight Change: A Systematic Umbrella Review. Behavioral Medicine, 37(1), 15-25. doi:10.1080/08964289.2010.543194

Schwimmer, J., Burwinkle, T., \& Varni, J. (2003). Health-related quality of life of severely obese children and adolescents. JAMA: Journal of The American Medical Association, 289(14), 18131819.

STOP Obesity Alliance. (2014). Why weight? A guide to discussing obesity and health with your patients. Retrieved from http://www.stopobesityalliance.org/wpcontent/themes/stopobesityalliance/pdfs/STOPProvider-Discussion-Tool.pdf

Stratis Health. (201r). Rural health. Retrieved from http://www.culturecareconnection.org/matters/d iversity/ruralhealth.html

Texas Department of State Health Services. (2012). School Health Advisory Council: A Guide for Texas School Districts. Retrieved from https://www.dshs.state.tx.us/schoolhealth/sdhac. shtm

Tobin, K. J. (2013). Fast-food consumption and educational test scores in the USA. Child: Care, Health \& Development, 39(1), 118-124. doi:10.1111/j.1365-2214.2011.01349.x

Torre, S., Akré, C., \& Suris, J. (2010). Obesity Prevention Opinions of School Stakeholders: A Qualitative Study. Journal of School Health, 80(5), 233-239. doi:10.1111/j.17461561.2010.00495. $\mathrm{x}$

United States Department of Health and Human Services, Let'sMove.Gov. (2014). ALet's Move! - America's Move to Raise a Healthier Generation of Kids. Retrieved from http://www.letsmove.gov/initiatives

Utter, J. J., Scragg, R. R., Robinson, E. E., Warbrick, J. J., Faeamani, G. G., Foroughian,S. S., \& Swinburn, B. A. (2011). Evaluation of the Living 4 Life project: A youth-led, schoolbased obesity prevention study. Obesity Reviews, 12(51), 60.doi:10.1111/j.1467789X.2011.00905.

Walker, P.D., (2011, Spring). Winning the war against childhood obesity: The role of teachers and schools in early childhood education. Perspectives in Learning: A Journal of the College of Education \& Health Professions Columbus State University, 12(1), 40-45.

\section{About the authors:}

Travis Armstrong, Ed.D. is currently the Assistant Director of Special Education for Wichita Falls Independent School District.

Clementine Msengi, Ed.D. is a visiting assistant professor in the Department of Educational Leadership at Lamar University in Beaumont, Texas. Her published works and research interests focus on educational leadership, multicultural and global education, domestic and international health education, mentoring, and diversity and inclusion.

Sandra Harris, Ph.D. has been an educator for over 40 years as a teacher, principal, superintendent, and university professor. During that time she has written or co-authored 23 books and over 150 articles on the topic of leadership in schools. She is currently Professor of Educational Leadership for Lamar University, Beaumont, Texas. 